\title{
Parental preference for fluoride varnish: a new concept in a rapidly developing nation
}

\author{
This article was published in the following Dove Press journal: \\ Patient Preference and Adherence \\ 13 July 2016 \\ Number of times this article has been viewed
}

\author{
Mohamed A Hendaus ${ }^{1,2}$ \\ Hibaq A Jama' \\ Faisal J Siddiquil,3 \\ Sohair A Elsiddig' \\ Ahmed H Alhammadi ${ }^{1,2}$ \\ 'Department of Pediatrics, General \\ Academic Pediatrics Section, \\ Hamad Medical Corporation, Doha, \\ ${ }^{2}$ Department of Clinical Pediatrics, \\ Weill Cornell Medical College, \\ ${ }^{3}$ Pediatric Residency Program, Hamad \\ Medical Corporation, Doha, Qatar
}

Correspondence: Mohamed A Hendaus Department of Pediatrics, General Academic Pediatrics Section, Hamad Medical Corporation, PO Box 3050,

Doha, Qatar

Tel +974 44392239

Fax +974 44439571

Emailmhendaus@yahoo.com
Objective: The objective of this study was to investigate parental preference for fluoride varnish in a country where the average percentage of dental caries in young children is up to $\sim 73 \%$. Consequently, the aim of this study, despite being a pilot, was to create a nationwide project in the State of Qatar to promote oral health in children.

Methods: A cross-sectional perspective study was conducted at Hamad Medical Corporation in Qatar. Parents of children aged $\leq 5$ years were offered an interview survey. A total of 200 questionnaires were completed (response rate $=100 \%$ ). The study was conducted between December 1, 2014 and March 30, 2015, and included all children aged $>1$ year and $<5$ years who came to the outpatient clinics for well-child and sick visits. We also included children who were admitted to the inpatient wards.

Results: The mean age of participant children was $2.8 \pm 1.1$ years. When inquiring regarding parents' knowledge and awareness of dental health, we found that $>90 \%$ of families were aware that dental health affects the health of the whole body. The study showed that $\sim 70 \%$ of parents were not aware of the existence of fluoride varnish, but would allow a health provider to apply fluoride varnish. Furthermore, $\sim 80 \%$ of parents would not stop brushing their child's teeth and would not skip dentist appointments if varnish was to be applied. Approximately $40 \%$ of parents conveyed some concerns regarding the safety of fluoride varnish, despite being considered as a new concept. The main concern was that the child might swallow some of the fluoride. Another important concern expressed by parents was the availability of the fluoride varnish in all clinics.

Conclusion: The robust positive attitude of parents in this sample suggests that introducing fluoride varnish is feasible and acceptable in our community. Actions to augment fluoride varnish acceptability in the developing world, such as focusing on safety, could be important in the disseminated implementation of fluoride varnish.

Keywords: fluoride, parents, varnish, Qatar

\section{Introduction}

Dental caries is defined as damage of the teeth caused by plaque bacteria. The carbohydrate component of the food in the mouth is fermented by bacteria, producing acids leading to demineralization of the tooth enamel. This process is usually exacerbated by the lack of adequate dental hygiene. ${ }^{1}$ Dental caries is considered as the most common chronic disease in childhood. ${ }^{2}$ A Report of the Surgeon General stated that the prevalence of dental caries is seven times more common than hay fever and five times more common than asthma in children. The same report stated that more than one-half of elementary school children have at least one cavity or filling. In addition, offspring of low-income families have twice the risk of developing dental caries compared to children of higher economic status. ${ }^{3}$ 
The prevalence of dental caries in the State of Qatar is $73 \%{ }^{4}$ In the US, the prevalence among preschool children is approximately $28 \%,{ }^{5}$ and it can be as high as $60 \%$ in other countries. ${ }^{6}$

Bener et $\mathrm{al}^{4}$ studied the impact of dietary and lifestyle factors on the risk of dental caries among young children in Qatar. The group found that brushing once a day or less, bottle fed during infancy, being a female, overweight or obese, and monthly household income higher than US\$2,747 ( $\geq 10,000$ Qatari Riyals) were considered the main risk factors for dental caries in children residing in the State of Qatar.

Fluoride in toothpastes, water supplies, and professionally applied are well-known modes of preventing dental caries. ${ }^{7}$ A Cochrane study has shown that fluoride in varnishes, toothpastes, or gels can reduce dental caries by $26 \%$ in children and adolescents. ${ }^{8}$

Fluoride varnish is a condensed topical fluoride that is applied to the teeth using a small brush. ${ }^{9}$ The active ingredient of fluoride varnish is sodium fluoride with a concentration of $22,600 \mathrm{ppm}(2.26 \%) .{ }^{10}$ The proposed mechanism by which fluoride can protect against dental caries is by promoting enamel remineralization, reducing enamel demineralization, and a direct and indirect effect on bacterial cells. ${ }^{11}$ Its use is well accepted by infants and young children and can be applied by physicians and dentists. ${ }^{9}$ The American Academy of Pediatric Dentistry recommends the use of fluoride varnish every 3-6 months for infants and young children who are at risk of acquiring dental caries, ${ }^{10}$ initiating the process at the age of primary tooth eruption. ${ }^{12}$ In addition to preventing dental caries, one of the advantages of fluoride varnish is that it can be applied during the well-child visit, particularly for children who do not have access to dental care. ${ }^{10}$ Fluoride varnishes are a very feasible way of having preschoolers use professionally applied topical fluoride, where it takes only 1-4 minutes to apply. However, it is advisable that children avoid eating for 2 hours after the application of the varnish. In addition, it is recommended not to brush the teeth on the same day following the administration of fluoride varnish. This allows the varnish to stay in direct touch with the dental enamel for many hours. ${ }^{7}$

Several randomized controlled trials have concluded that fluoride varnish reduces the development of dental caries by $18 \%-63 \% .^{13-16}$

Dental treatment is considered expensive and can overwhelm the health care budget in some developing countries. ${ }^{17}$ Research has shown that dental caries prevention action in a primary health care setting can markedly reduce health care costs. ${ }^{18}$
Pediatricians might be the only accessible source of dental care to children who cannot afford a visit to the dentist. ${ }^{19}$ Therefore, it is crucial that a pediatric physician is acquainted with the pathophysiology of dental caries and the application of fluoride varnish, while simultaneously providing education and prevention counseling of oral health during a well-child visit. ${ }^{20}$ No published literature shows that professionally applied fluoride varnish is a hazard determinant for enamel fluorosis in young children. Appropriate application method decreases the probability that a child will swallow varnish during its application and reduces the total amount of fluoride ingested, as the varnish remains on the teeth over several hours. ${ }^{21}$

There is no data or studies about parental preference for fluoride varnish in developing countries such as the State of Qatar. This study provides data for future research and can be used in other countries with a goal of improving oral health in children. Consequently, the aim of this study, despite being a pilot, was to create a nationwide project to promote oral health in children via counseling, awareness, and the introduction of new modes of dental caries prevention, such as fluoride varnish.

\section{Materials and methods Study design, period, setting, and participants}

A cross-sectional perspective study through an interview survey in the inpatient and outpatient department was conducted at Hamad Medical Corporation, the only tertiary care, and teaching hospital in the State of Qatar. Our target population included parents who had a child or children aged $>1$ year and $<5$ years. The plan was to recruit 200 participants as a pilot study. The study was conducted between December 1, 2014 and March 30, 2015, and included all children aged $>1$ year and $<5$ years who came to the outpatient clinics for well-child and sick visits. We also included children who were admitted to the inpatient wards. Children with cerebral palsy or disabilities were excluded as oral health could be a challenge. A total of 200 questionnaires were completed (response rate $=100 \%$ ).

We utilized an anonymous modified interview-based assessment of parental acceptability and preferences, with some information acquired from published studies, ${ }^{22-28}$ and modified it to meet our patient population cultures.

The Medical Research Center in our institution validated the questionnaire that was composed of a total of 20 items. These sections addressed parents and children demographics, oral hygiene habits, parental knowledge, awareness of oral 
health, and perception of fluoride varnish. Participants were recruited through direct personal contact during arrival and departure times in the inpatient pediatric wards and outpatient pediatric clinics. One parent for each household with a child aged 1-5 years at the center was eligible to participate. Verbal informed consent was obtained at the time of the interview and all materials were available in Arabic and English. Participants were informed as to why the information was being collected and how it would be used. Prior to the start of the interview, a statement was read to parents informing them that their participation was voluntary and we indicated that their answers were anonymous and confidential. For every single parent, we explained the procedure of fluoride varnish and its use in Western countries. A member of the research team initially explained that the proposed new treatment is effective and safe and does not substitute current oral health. In regard to the section related to fluoride varnish, the interviewer verbally described the procedure supported by illustrated pictures. Thereafter, the member of the research team verified that the caregiver had understood the basic information of fluoride varnish via verbal feedback.

Parents did not receive any type of monetary or nonmonetary compensation for participating in the study. This study was approved by Hamad Medical Corporation-Medical Research Center with reference number 14507/14.

\section{Statistical analysis}

Qualitative and quantitative data values were displayed as frequencies along with percentages and mean \pm standard deviation, and median and range. Descriptive statistics were utilized to summarize demographic and all other characteristics of the participants. Associations between two or more qualitative or categorical variables were appraised using chi-square test. Pictorial presentations were used to simplify the display of results. A two-sided $P$-value $<0.05$ was considered to be statistically significant. All statistical analyses were conducted using statistical package SPSS, version 19.0 (IBM Corporation, Armonk, NY, USA).

\section{Results}

The mean age of participant children was $2.8 \pm 1.1$ years. Demographics and socioeconomic factors are summarized in Tables 1 and 2. The methods of oral hygiene followed in our country differ, as seen in Figure 1. When inquiring regarding parents' knowledge and awareness of dental health, we found that $>90 \%$ of families were aware that dental health affects the whole body health (Figure 2). In the section related to fluoride varnish, the study showed that $\sim 70 \%$ of parents were
Table I Demographics of children and parents

\begin{tabular}{lllll}
\hline & Minimum & Maximum & Mean & $\begin{array}{l}\text { Standard } \\
\text { deviation }\end{array}$ \\
\hline Child's age & 1.0 & 5.0 & 2.848 & $1.145 \mathrm{I}$ \\
Order of child & $\mathrm{I}$ & 6 & 1.87 & 1.240 \\
Father's age & 22 & 53 & 33.92 & 5.848 \\
Mother's age & 20 & 57 & 29.63 & 4.909 \\
Sibling(s) with caries & 0 & 5 & 0.93 & 0.975 \\
\hline
\end{tabular}

not aware of the existence of fluoride varnish, but would allow a health provider to apply fluoride varnish. Furthermore, $\sim 80 \%$ of parents would not stop brushing their child's teeth and would not skip dentist appointments if varnish were to be applied. Approximately $40 \%$ of parents conveyed some concerns regarding the safety of fluoride varnish, despite being considered as a new concept. The main concern was that the child might swallow some of the fluoride. Another important concern expressed by parents was the availability of the fluoride varnish in all clinics (Figure 3). Finally, it appears that higher education was positively associated with knowledge about fluoride varnish and willingness to apply fluoride varnish, but the results were not statistically significant $(P>0.05)$. It was observed that both father's and mother's age were significantly associated with increased reception to the idea of applying fluoride varnish $(P=0.004$ and $P=0.007$, respectively). More specifically, the younger the father's age (among the age group $\leq 30$ years, 77.5\% agreed with the idea of applying fluoride varnish; $68 \%$ in the age group between 30 and 40 years, and 53.8\% in the age group $>40$ years; $P=0.004$ ) and mother's age (among the age group $\leq 30$ years, $74.8 \%$ agreed with the idea of applying fluoride varnish, $59.6 \%$ in the age group between 30 and 35 years, and $55.6 \%$ in the age group $>35$ years; $P=0.007$ )

Table 2 Socioeconomic characteristics of parents

\begin{tabular}{lll}
\hline & Frequency & Percentage \\
\hline $\begin{array}{lll}\text { Mother's working status } \\
\text { Housewife }\end{array}$ & 128 & 64 \\
Working & 72 & 36 \\
$\begin{array}{l}\text { Father's level of education } \\
\text { <High school }\end{array}$ & 2 & 1 \\
High school & 38 & 19 \\
Some college & 117 & 58 \\
College graduate & 38 & 19 \\
Postgraduate & 5 & 2.5 \\
Mother's level of education & 8 & \\
<High school & 64 & 4 \\
High school & 94 & 32 \\
Some college & 32 & 47 \\
College graduate & 2 & 16 \\
Postgraduate & & \\
\hline
\end{tabular}




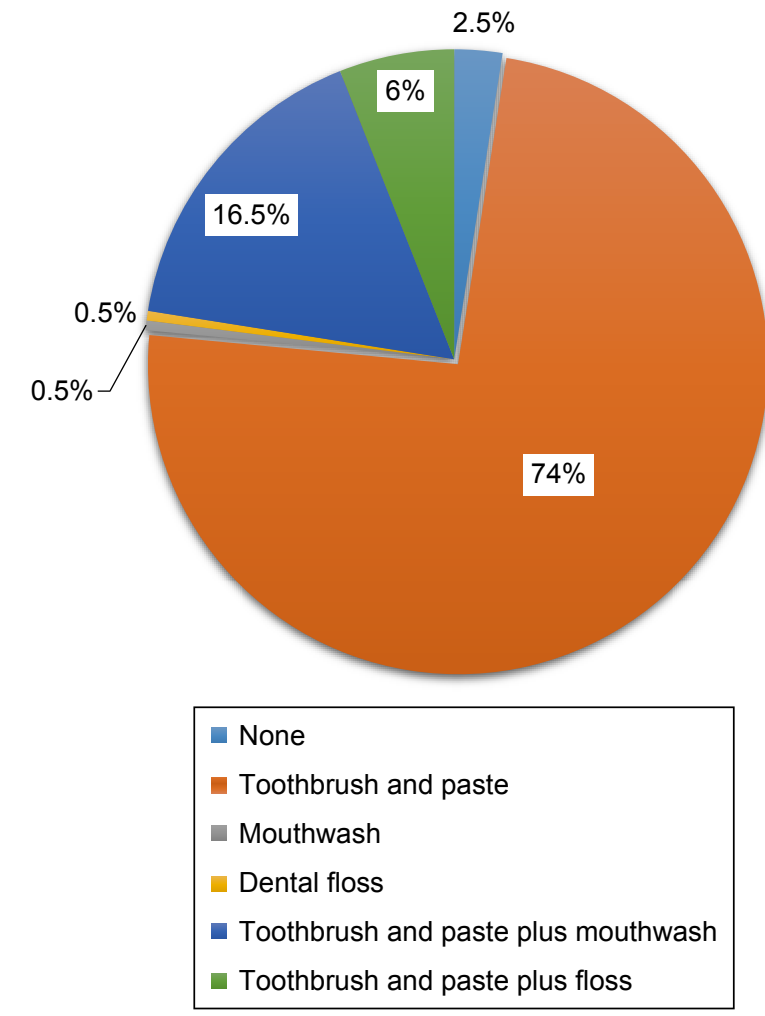

Figure I Methods of dental hygiene in participants.

were positively and significantly associated with increased reception to the idea of applying fluoride varnish.

\section{Discussion}

This study presents a comprehensive overview of the oral health, knowledge, and parental preference for fluoride varnish.
To the best of our knowledge, this is the first study of its kind that explored these issues among parents of preschool children in the State of Qatar, and perhaps worldwide. It was noticed that the use of oral hygiene methods, such as dental floss in combination with toothpaste, was very low $(6 \%)$, and we believe that this could be related to the deficiency of oral health education. However, parents showed increased awareness of the association between oral health and total body well-being. This is important because linking oral health to systemic well-being might assist bolster oral health care and oral self-care practice among young children. ${ }^{23}$ This investigation showed significant parental lack of knowledge of fluoride varnish in a nation where the prevalence of dental caries is high. Dental caries preventive behaviors should begin during infancy; therefore, the matter of parental acceptability of treatment for children as young as 1 year of age is crucial. Investigating parents' knowledge and preference for fluoride varnish is essential prior to implementing effective curriculums to manage and prevent dental caries in young children. ${ }^{23,28}$

Moreover, a very important and crucial point in this study was that $\sim 70 \%$ of parents would allow health care providers to apply fluoride varnish. Proper counseling and education can assist in implementing better oral health, ${ }^{29}$ and perhaps increase the percentage of fluoride varnish receptiveness. Health care providers, especially pediatricians, should take the opportunity to extend counseling to parents regarding fluoride varnish application. ${ }^{30}$ Motivational interviewing (MI) is a counseling method using a patient-centered approach that

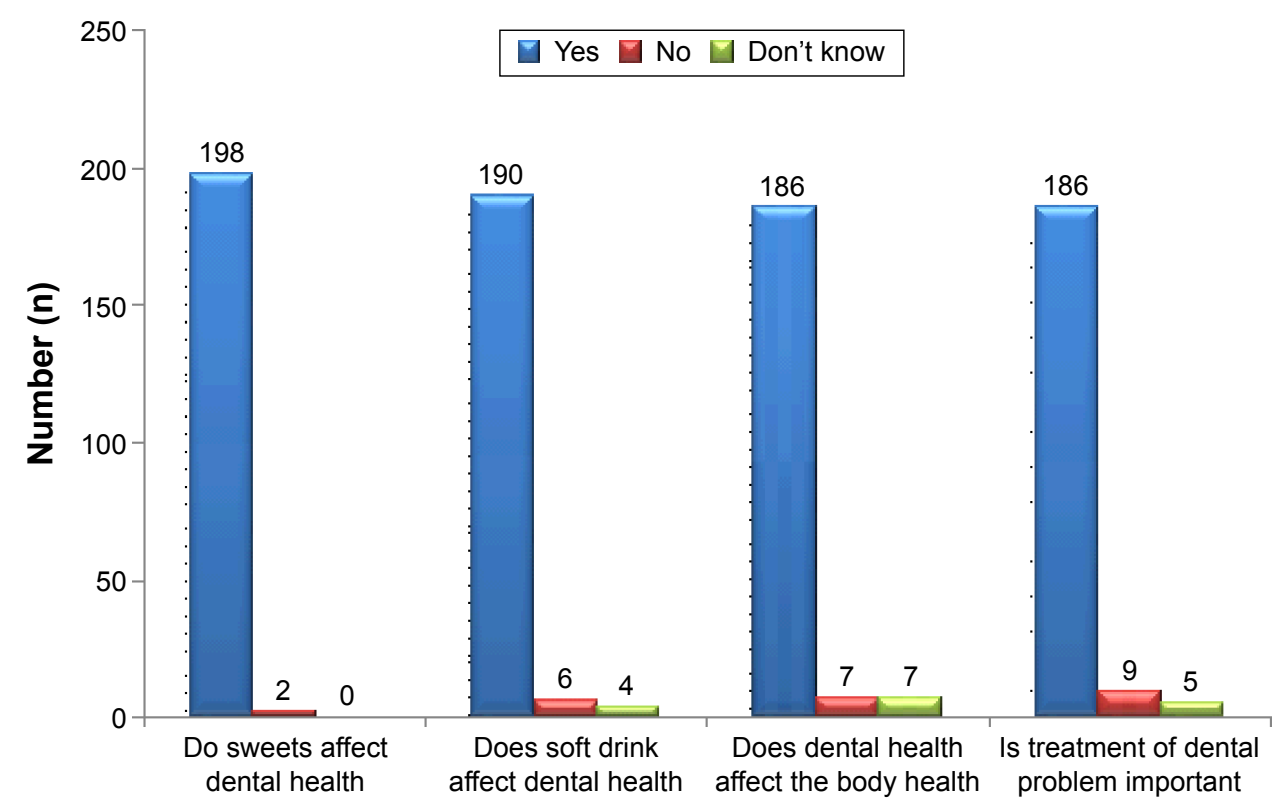

Figure 2 Parental knowledge and awareness of dental health. 


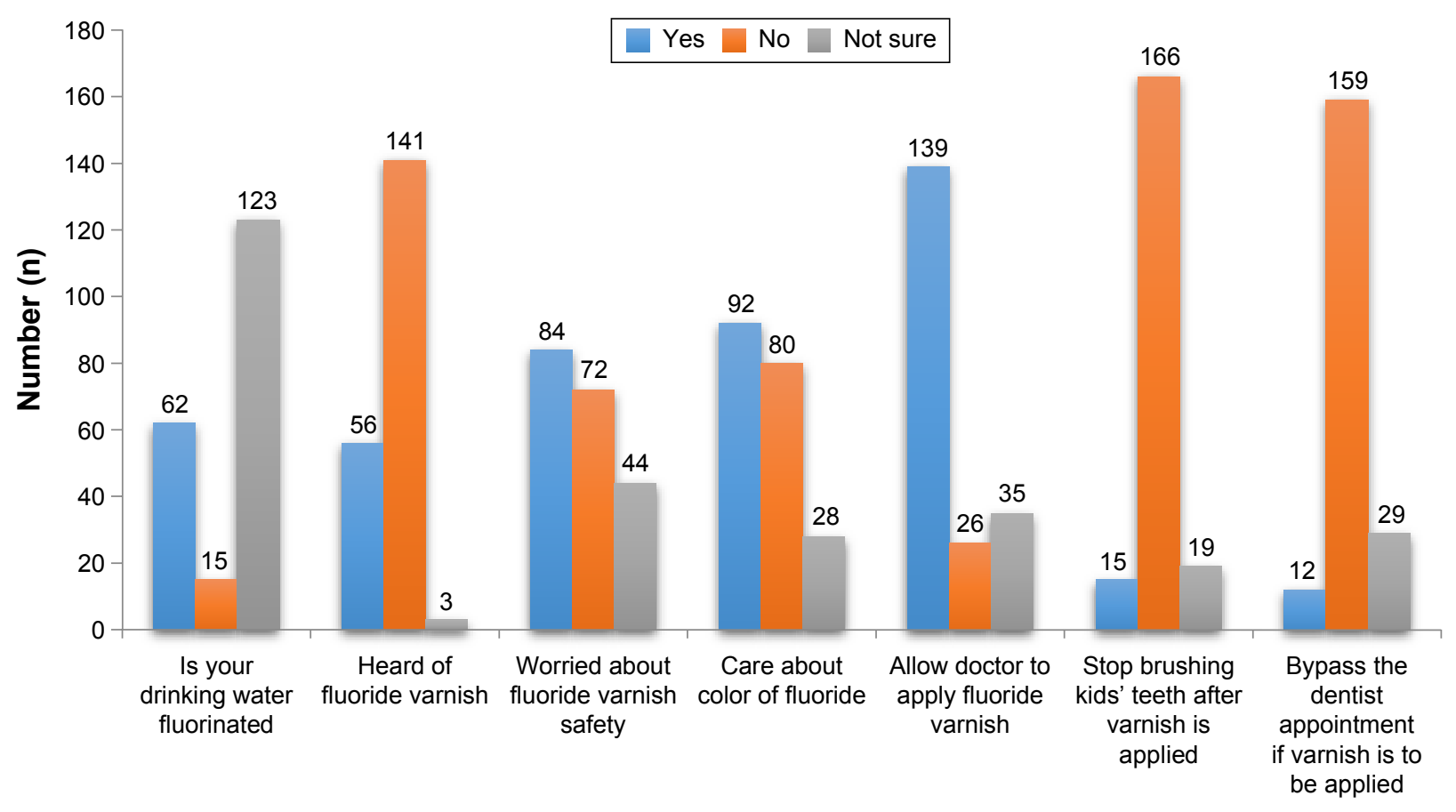

Figure 3 Answers to statements related to the role of fluoride in oral health.

works on facilitating and engaging intrinsic motivation within the patient in order to change behavior. ${ }^{31}$ The literature has shown that MI is useful in behavior change in a variety of health disorders. ${ }^{32}$ Weinstein et al ${ }^{33}$ conducted a study with an aim of comparing the efficacy of an MI visit with traditional health education for mothers of young children at high risk of developing dental caries. The study concluded that children in the MI group displayed less dental caries than those in the traditional health education group (odds ratio $=0.35,95 \%$ confidence interval $=0.15-0.83$ ).

In our participant population, there were no significant associations between individual factors such as parental education, siblings with dental caries, and parent knowledge of fluoride as a supplement to oral health maintenance.

There have been very limited investigations addressing acceptability of preventive treatments for children. ${ }^{26}$ This is lamentable, as previous research has shown that oral health care usage and outcomes are driven in part by community and cultural aspects that must be taken into consideration in the effort to improve children's oral health. ${ }^{34-36}$ Evans et al ${ }^{37}$ proposed "the Happy Teeth fluoride varnish programme" in East London. The program comprised of fluoride varnish applications associated with school dental screenings for 3- to 6-year olds. The study, which included up to 1,822 children with at least one fluoride varnish application, concluded that the program was very well received by participating parents/ caregivers, school staff, and children. Berg et $\mathrm{al}^{24}$ conducted a study comparing parents' and children's preferences for new fluoride varnish. The study, which included children aged 4-18 years, showed that efficacy of the fluoride varnish was the main point parents care about. Lam et $\mathrm{al}^{27}$ investigated preferences for food products containing xylitol and concluded that most foods were graded as acceptable by the children. Adams et a ${ }^{25}$ studied the caregiver acceptability and preferences for early childhood caries preventive treatments for Hispanic children by recruiting 211 parents/caregivers. The treatments appraised were: fluoride varnish, tooth brushing with fluoride toothpaste, xylitol in food for children, xylitol gum, and chlorhexidine rinse. The study concluded that all five treatments were highly acceptable; however, when selecting among regimens, overall, fluoride varnish and tooth brushing were preferred over other treatments.

Wong et $\mathrm{a}^{38}$ studied the attitudes of Chinese parents toward the oral health of their children with caries and found that parental lack of dental education, deficiency of social support in the pursuit of dental treatment, fear of sedation for dental procedures, and cultural belief that does not back the preservation of primary dentition were among the major barriers in the implementation of proper oral hygiene habits. ${ }^{26}$ Chhabra and Chhabra ${ }^{39}$ studied parental knowledge, attitudes, and cultural beliefs regarding oral health and dental care of preschool children in an Indian population. The authors concluded that the deficiency of awareness and knowledge, myths related to the dentist's visit, and dental apprehension 
of parents were the most common obstacles to the prevention of dental caries in young children. Al-Omiri et $\mathrm{al}^{23}$ studied the oral health attitudes, knowledge, and behavior among school children in North Jordan, where 557 participants were recruited.

The children in the study also identified the significance of oral health to the well-being of the whole body. Parents were not enthusiastic about making sure that their children received frequent oral health care. Parental knowledge and attitudes about the significance of dental care and their apprehensions about dental treatment affected their children's dental care.

This study has numerous strengths, particularly both the quantitative and qualitative responses from parents included by us, which resulted in better understanding of the basic findings regarding oral health in general and parents' preference for fluoride varnish in particular.

These findings will allow us to propose a comprehensive national educational program to introduce fluoride varnish and overall oral health awareness with the ultimate goal of improving children's well-being in the State of Qatar. Educational oral hygiene programs in the State of Qatar have been mainly channeled to the community to a limited extent by one formal dental school in Qatar. Lamentably, these attempts are very few and inadequate nationwide; hence, there is a need for primary care physicians, especially pediatricians, to greatly contribute in oral health education.

This study has limitations. For instance, this is a pilot study, and therefore we suggest that our investigation be replicated using a larger sample for better generalization. Moreover, there might be a possibility that there are specific characteristics related to preferences that were not appraised in this study or that power was not high enough for these appraisals.

\section{Conclusion}

The robust positive attitude of parents in this sample suggests that introducing fluoride varnish is feasible and acceptable in our community. Actions to augment fluoride varnish acceptability in the developing world, such as focusing on safety, could be important in the disseminated implementation of fluoride varnish.

\section{Acknowledgments}

This research was presented at American Academy of Pediatrics, AAP Experience National Conference and Exhibition conference on October 24-27, 2015. In addition, the authors would like to thank the Medical Research Center at Hamad Medical Corporation in Qatar for the ethical approval of this project.

\section{Disclosure}

The authors report no conflicts of interest in this work.

\section{References}

1. Featherstone JD. Dental caries: a dynamic disease process. Aust Dent J. 2008;53(3):286-291

2. Al-Darwish M, El Ansari W, Bener A. Prevalence of dental caries among 12-14 year old children in Qatar. Saudi Dent J. 2014;26(3): $115-125$.

3. National Institute of Dental and Craniofacial Research. Oral Health in America: A Report of the Surgeon General (Executive Summary). Updated: March 7, 2014. Available from: http://www.nidcr.nih. gov/DataStatistics/SurgeonGeneral/Report/ExecutiveSummary.htm. Accessed February 15, 2015.

4. Bener A, Al Darwish MS, Tewfik I, Hoffmann GF. The impact of dietary and lifestyle factors on the risk of dental caries among young children in Qatar. J Egypt Public Health Assoc. 2013;88(2):67-73.

5. National Center for Caries Disease Prevention and Health Promotion. Oral Health Resources - Children's Oral Health Overview; 2006. Available from: http://www.cdc.gov/oralhealth/pdfs/oral_health_ strategic_plan.pdf. Accessed February 28, 2016.

6. Ministry of Health. National Oral Health Coordination. SB Brazil Project 2003. Oral health status of the population. Main results. Brasília; 2004. Available from: http://cfo.org.br/wp-content/uploads/2009/10/04_0347_M.pdf. Accessed February 28, 2016. Portuguese.

7. Carvalho DM, Salazar M, Oliveira BH, Coutinho ES. Fluoride varnishes and decrease in caries incidence in preschool children: a systematic review. Rev Bras Epidemiol. 2010;13(1):139-149.

8. Marinho VC, Higgins JP, Sheiham A, Logan S. Fluoride toothpastes for preventing dental caries in children and adolescents. Cochrane Database Syst Rev. 2003;(1):CD002278.

9. American Dental Association Council on Scientific Affairs. Professionally applied topical fluoride: evidence-based clinical recommendations. J Am Dent Assoc. 2006;137(8):1151-1159.

10. American Academy of Pediatric Dentistry. Guideline on Fluoride Therapy. Chicago, IL: American Academy of Pediatric Dentistry; 2013. Available from: www.aapd.org/media/Policies_Guidelines/G_fluoridetherapy. pdf. Accessed May 20, 2014

11. Rošin-Grget K, Peroš K, Sutej I, Bašić K. The cariostatic mechanisms of fluoride. Acta Med Acad. 2013;42(2):179-188.

12. U.S. Preventive Services Task Force. Prevention of Dental Caries in Children from Birth through Age 5 Years: US Preventive Services Task Force Recommendation Statement. Rockville, MD: US Preventive Services Task Force; 2014. Available from: www.uspreventiveservicestaskforce. org/uspstf/uspsdnch.htm. Accessed May 20, 2014.

13. Bader JD, Rozier RG, Lohr KN, Frame PS. Physicians' roles in preventing dental caries in preschool children: a summary of the evidence for the U.S. Preventive Services Task Force. Am J Prev Med. 2004;26(4): 315-325.

14. Lawrence HP, Binguis D, Douglas J, et al. A 2-year communityrandomized controlled trial of fluoride varnish to prevent early childhood caries in Aboriginal children. Community Dent Oral Epidemiol. 2008;36(6):503-516.

15. Slade GD, Bailie RS, Roberts-Thomson K, et al. Effect of health promotion and fluoride varnish on dental caries among Australian Aboriginal children: results from a community-randomized controlled trial. Community Dent Oral Epidemiol. 2011;39(1):29-43.

16. Weintraub JA, Ramos-Gomez F, Jue B, et al. Fluoride varnish efficacy in preventing early childhood caries. J Dent Res. 2006;85(2): $172-176$. 
17. World Health Organization. Oral Health Promotion: An Essential Element of a Health-Promoting School. WHO Information Series on School Health (Document Eleven). Geneva: WHO; 2003. WHO/ NMH/NPH/ORH/School/03.3. Available from: http://www.who.int/ oral_health/media/en/orh_school_doc11.pdf. Accessed February 28, 2016.

18. Stearns SC, Rozier RG, Kranz AM, Pahel BT, Quiñonez RB. Cost-effectiveness of preventive oral health care in medical offices for young Medicaid enrollees. Arch Pediatr Adolesc Med. 2012;166(10) 945-951.

19. Lewis C, Lynch H, Richardson L. Fluoride varnish use in primary care: what do providers think? Pediatrics. 2005;115(1):e69-e76.

20. Segura A, Boulter S, Clark M, et al. Maintaining and improving the oral health of young children. Pediatrics. 2014;134(6):1224-1229.

21. MMWR. Center for Disease Control and Prevention. Recommendations for Using Fluoride to Prevent and Control Dental Caries in the United States. Available from: http://www.cdc.gov/mmwr/preview/mmwrhtml/ rr5014a1.htm. Accessed February 29, 2016.

22. Adams SH, Rowe CR, Gansky SA, Cheng NF, Barker JC, Hyde S. Caregiver acceptability and preferences for preventive dental treatments for young African-American children. J Public Health Dent. 2012;72(3): $252-260$

23. Al-Omiri MK, Al-Wahadni AM, Saeed KN. Oral health attitudes, knowledge, and behavior among school children in North Jordan. J Dent Educ. 2006;70(2):179-187.

24. Berg J, Riedy CA, Tercero A. Patient and parental perception of a new fluoride varnish. Compend Contin Educ Dent. 2006;27(11):614-618.

25. Adams SH, Hyde S, Gansky SA. Caregiver acceptability and preferences for early childhood caries preventive treatments for Hispanic children. J Public Health Dent. 2009;69(4):217-224.

26. Hyde S, Gansky SA, Gonzalez-Vargas MJ, et al. Developing an acceptability assessment of preventive dental treatments. J Public Health Dent. 2009;69(1):18-23.

27. Lam M, Riedy CA, Coldwell SE, Milgrom P, Craig R. Children's acceptance of xylitol-based foods. Community Dent Oral Epidemiol. 2000;28:97-101.

28. Smyth E, Caamano F, Fernández-Riveiro P. Oral health knowledge, attitudes and practice in 12-year-old schoolchildren. Med Oral Pathol Oral Cir Bucal. 2007;12(8):E614-E620.
29. Ab-Murat N, Watt RG. Chief dentists' perceived strengths and weaknesses of oral health promotion activities in Malaysia. Annal Dent Univ Malaya. 2006;13:1-5.

30. Gussy MG, Waters EB, Riggs EM, Lo SK, Kilpatrick NM. Parental knowledge, beliefs and behaviours for oral health of toddlers residing in rural Victoria. Aust Dent J. 2008;53(1):52-60.

31. Saffari M, Pakpour AH, Mohammadi-Zeidi I, Samadi M, Chen H. Longterm effect of motivational interviewing on dietary intake and weight loss in Iranian obese/overweight women. Health Promot Perspect. 2014; 4(2):206-213.

32. Burke BL, Dunn CW, Atkins DC, Phelps JS. The emerging evidence base for motivational interviewing: a meta analytic and qualitative inquiry. J Cogn Psychother. 2004;18:309-322.

33. Weinstein P, Harrison R, Benton T. Motivating mothers to prevent caries: confirming the beneficial effect of counseling. J Am Dent Assoc. 2006;137(6):789-793.

34. Butani Y, Weintraub JA, Barker JC. Assessment of the literature on oral health-related cultural beliefs for four racial/ethnic groups. $B M C$ Oral Health. 2008;8:26.

35. Hilton IV, Stephen S, Barker JC, Weintraub JA. Cultural factors and children's oral health care: a qualitative study of carers of young children. Community Dent Oral Epidemiol. 2007;35(6):429-438.

36. Kelly SE, Binkley CJ, Neace WP, Gale BS. Barriers to care-seeking for children's oral health among low-income caregivers. Am J Pub Health. 2005;95(8):1345-1351.

37. Evans P, Pearson N, Simons D. A school-based oral health intervention in East London: the Happy Teeth fluoride varnish programme. Br Dent J. 2013;215(8):E14.

38. Wong D, Perez-Spiess S, Julliard K. Attitudes of Chinese parents toward the oral health of their children with caries: a qualitative study. Pediatr Dent. 2005;27(6):505-512.

39. Chhabra N, Chhabra A. Parental knowledge, attitudes and cultural beliefs regarding oral health and dental care of preschool children in an Indian population: a quantitative study. Eur Arch Paediatr Dent. 2012 13(2):76-82.
Patient Preference and Adherence

\section{Publish your work in this journal}

Patient Preference and Adherence is an international, peer-reviewed, open access journal that focuses on the growing importance of patient preference and adherence throughout the therapeutic continuum. Patient satisfaction, acceptability, quality of life, compliance, persistence and their role in developing new therapeutic modalities and compounds to optimize

\section{Dovepress}

clinical outcomes for existing disease states are major areas of interest for the journal. This journal has been accepted for indexing on PubMed Central. The manuscript management system is completely online and includes a very quick and fair peer-review system, which is all easy to use. Visit http://www. dovepress.com/testimonials.php to read real quotes from published authors. 